\title{
Performance of smooth and micro-fin tubes in high mass flux region of R-134a during evaporation
}

Jittraporn Wongsa-ngam, Thipjak Nualboonrueng, Somchai Wongwises

1

Heat and Mass Transfer (2002)

DOI 10.1007/s00231-002-0397-5

Unfortunately there were two errors in Conclusion section.

In topic 3 the sentence should read:

3. The average heat transfer coefficient and average pressure drop for the $9.52 \mathrm{~mm}$ OD micro-fin tube are $50 \%$ to $100 \%$ and $10 \%$ to $60 \%$ greater than for the smooth tube, respectively.

The subtopic 3 in topic 4 , the sentence should read:

3) The two-phase friction multiplier $\phi_{l}^{2}$ for the smooth tube;

Without Abstract

The online version of the original article can be found at http:// dx.doi.org/10.1007/s00231-002-0397-5

J. Wongsa-ngam

Energy Division, The Joint Graduate School of Energy

and Environment, King Mongkut's University of Technology

Thonburi, Bangmod, Bangkok 10140, Thailand

T. Nualboonrueng, S. Wongwises $(\varangle)$

Fluid Mechanics, Thermal Engineering and Multiphase Flow Research

Laboratory (FUTURE), Department of Mechanical Engineering,

King Mongkut's University of Technology Thonburi, Bangmod,

Bangkok 10140, Thailand

E-mail: somchai.won@kmutt.ac.th

Tel.: +662-470-9115

Fax: +662-470-9111 